\title{
Atlas of Age- and Tissue-specific DNA Methylation during Early Development of Barley (Hordeum vulgare)
}

\author{
Moumouni Konate ${ }^{1,6}$, Mike J. Wilkinson ${ }^{2 *}$, Benjamin T. Mayne ${ }^{3}$, Eileen S. Scott ${ }^{4}$, Bettina \\ Berger ${ }^{4,5}$ and Carlos M. Rodríguez López ${ }^{4,6, *}$ \\ 1 Institut de l'Environnement et de Recherche Agricole (INERA), Station de Farako-Ba, 01 BP 910 Bobo- \\ Dioulasso 01, Burkina Faso. \\ 2 Pwllpeiran Upland Research Centre, Institute of Biological, Environmental and Rural Sciences, Penglais \\ Campus, Aberystwyth, Ceredigion, SY23 3FG, UK. \\ 3 Robinson Research Institute, School of Medicine, The University of Adelaide, SA 5005 Australia. \\ 4 School of Agriculture, Food and Wine, Waite Research Institute, The University of Adelaide, Waite \\ Campus, PMB 1, Glen Osmond, SA 5064, Australia. \\ 5 The Plant Accelerator, Australian Plant Phenomics Facility, School of Agriculture, Food and Wine, Waite \\ Research Institute, The University of Adelaide, Waite Campus, PMB 1, Glen Osmond, SA 5064, Australia. \\ 6 Environmental Epigenetics and Genetics Group; Department of Horticulture, College of Agriculture, Food \\ and Environment, University of Kentucky, Lexington, KY 40546*
} * Correspondence: carlos.rodriguezlopez@adelaide.edu.au, Phone: +61 88313 0774; mjw19@aber.ac.uk,
Phone: +44 (0) 1970823204

\begin{abstract}
The barley (Hordeum vulgare) genome comprises over 32,000 genes, with differentiated cells expressing only a subset of genes; the remainder being silent. Mechanisms by which tissuespecific genes are regulated are not entirely understood, although DNA methylation is likely to be involved. DNA methylation patterns are not static during plant development, but it is still unclear whether different organs possess distinct methylation profiles. Methylation-sensitive GBS was used to generate DNA methylation profiles for roots, leaf-blades and leaf-sheaths from five barley varieties, using seedlings at the three-leaf stage. Differentially Methylated Markers (DMMs) were characterised by pairwise comparisons of roots, leaf-blades and leaf-sheaths of three different ages. While very many DMMs were found between roots and leaf parts, only a few existed between leafblades and leaf-sheaths, with differences decreasing with leaf rank. Organ-specific DMMs appeared to target mainly repeat regions, implying that organ differentiation partially relies on the spreading of DNA methylation from repeats to promoters of adjacent genes. Furthermore, the biological functions of differentially methylated genes in the different organs correlated with functional specialisation. Our results indicate that different organs do possess diagnostic methylation profiles and suggest that DNA methylation is important for both tissue development and differentiation and organ function.
\end{abstract}

Keywords: epigenomics, hordeum vulgare, leaf, root, tissue-specific methylation, developmental epigenomics

\section{Introduction}

DNA methylation is an important characteristic of plant genomes [1,2], and can occur in all cytosine contexts (CG, CHG and $\mathrm{CHH}$, where $\mathrm{H}=\mathrm{A}, \mathrm{C}$ or $\mathrm{T}$ ) [3]. The effect of DNA methylation variants on plant development has been demonstrated through methylation alteration tests, which led to plant abnormalities $[4,5]$. Furthermore, DNA methylation has been reported to vary from tissue 
to tissue in many species [6-10], and these methylation changes seemed to be essential for normal plant development [11,12].

Additionally, tissue-specific methylation was proposed to have a strong correlation with the differential expression of some tissue-specific genes. Examples include tissue-specific pigmentation in maize, which is reported to be under epigenetic control [13], and differential gene expression between organs attributed to differentially methylated regions in soybean [14] and sorghum [10]. These studies extended our understanding of the functional importance of tissue-specific DNA methylation, including its role in setting developmental trajectories $[9,13,15]$.

A substantial proportion of developmentally expressed genes have alternative promoters (multiple promoters that regulate the same gene) which are under different regulatory programmes [16]. Maunmakea et al. [17] proposed that alternative promoters are, at least sometimes, controlled by intragenic DNA methylation. This form of developmental gene regulation is reasoned to be dependent on transposon activity [16] and by implication would mean that silencing of transposons due to DNA methylation may be central to tissue-specific gene expression. Also, tissue-specific gene expression has been associated with methylation changes in promoter regions $[2,18,19]$, especially CG islands within promoters [20]. These studies indicate that tissue-specific gene expression does not rely on a single methylation pattern in the genome but, probably, on a combination of variable DNA methylation features.

The magnitude of differential methylation between tissues has been the subject of controversy. It was believed that significant distinctive DNA methylation existed only between specialised tissues such as endosperm, pollen, leaves and roots [9,10,21,22]. Nevertheless, many of these studies also showed that differential DNA methylation between organs, such as roots and leaves, was minor in rice [23], maize [24], sorghum [10] and Arabidopsis [9]. DNA methylation differences between roots and leaves were small in both ${ }^{\mathrm{m}} \mathrm{CG}$ and ${ }^{\mathrm{m}} \mathrm{CHG}$ contexts $[9,10]$, with about $1 \%$ and $5 \%$ divergence, respectively, reported in Arabidopsis [9]. While these studies of differential DNA methylation between tissues generally compared the overall methylation levels $[9,10,24]$, these results differ from comparisons made with differentially methylated markers (DMMs) between the same tissues [10], probably due to differences in methylation profiling methods, making it difficult to compare results from different studies. Therefore, it is difficult to know whether differences in the results concerning tissue-specific DNA methylation are due to the plant species or to the approach taken. The study of DNA methylation patterns in plant tissues is important for a better understanding of how these epigenetic markers determine tissue differentiation. Thus, further investigation is warranted to clarify organ specificity of cytosine methylation and the distribution patterns of tissue-specific DNA methylation markers in the plant genome.

To undertake such an investigation, we used barley, a globally important cereal crop, the genome of which has been sequenced recently [25]. The availability of a reference genome made barley a model for the study of cereal crops such as wheat, oats or rye. In this study, we assessed differential DNA methylation between two barley (Hordeum vulgare) organs (roots and leaves), using methylation-sensitive genotyping by sequencing (ms-GBS) on five genetically distinct varieties.. For the sake of simplicity and consistency with the literature, roots and leaves or leaf parts (sheath, blade) may be referred to here as tissues and not organs.

\section{Results}

Methylation-sensitive genotyping by sequencing

The sequencing of the 170 samples of barley tissue which met DNA quality requirements yielded over 900 million raw reads, with more than $91 \%$ bases above Q30 (99.9\% accuracy of base call [26]) across all samples (Table 1). Of these reads, 99.27\% contained the barcode and EcoRI/MspI adapters ligated during library construction. Further filtering was performed to retain reads that strictly aligned with the barley reference genome. In this way, we obtained nearly 450 million reads $(50.10 \%)$, with a mean of $2,637,916$ high quality reads per sample. These high-quality reads accounted for 913,697 sequence tags, representing $32.30 \%$ of the $2,828,642$ CCGG sites in the barley genome. Of 
95

96

97

these sequence tags, 748,594 (80.62\%) showed some form of polymorphism for methylation between samples.

Table 1: Data yields from ms-GBS, generated using the Illumina HiSeq 2500 platform.

\begin{tabular}{cc}
\hline Raw reads & $901,617,058$ \\
Reads that matched barcodes & $895,013,295$ \\
Reads aligned to barley reference genome & $448,445,748$ \\
Samples & 170 \\
Average reads per sample & $2,637,916$ \\
Total unique tags & 913,697 \\
Polymorphic tags & 748,594 \\
\hline
\end{tabular}

Estimation of tissue- and tissue rank- dependent epigenetic differentiation

The PC-LDA plots revealed clear evidence of structuring of methylation between samples (Fig. 1a). A 3D plot using the first three discriminant factors (DF1, DF2 and DF3) revealed that blades and sheaths were further grouped according to the rank of the leaf from which they were harvested. The distance between blades and sheaths seems to shrink with leaf rank (Fig. 1b). This leaf rankdependent grouping was also supported by hierarchical cluster analysis (HCA) of the distances between sample group centres (Fig. 1c), based on the Mahalanobis distance [27,28], and sample clusters matched the leaf developmental age (Fig. 1c)). Leaf rank-dependent DNA methylation differences were further assessed between tissues by comparing the methylation profiles of blades and sheaths for each rank of leaf appearance. No DMMs were observed between the three leaf blades, whereas sheaths 1 and 3 presented 18 DMMs (Table 2). 
(a) blade $\bullet$ root $\bullet$ sheath

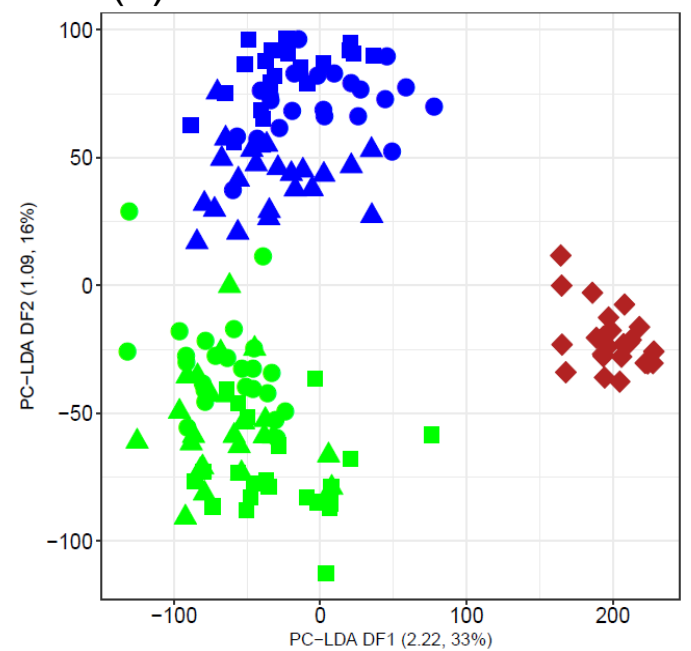

- blade1 $\triangle$ blade3 $\square$ sheath1 $\triangle$ sheath3

- blade2 $\diamond$ root sheath2 (c)

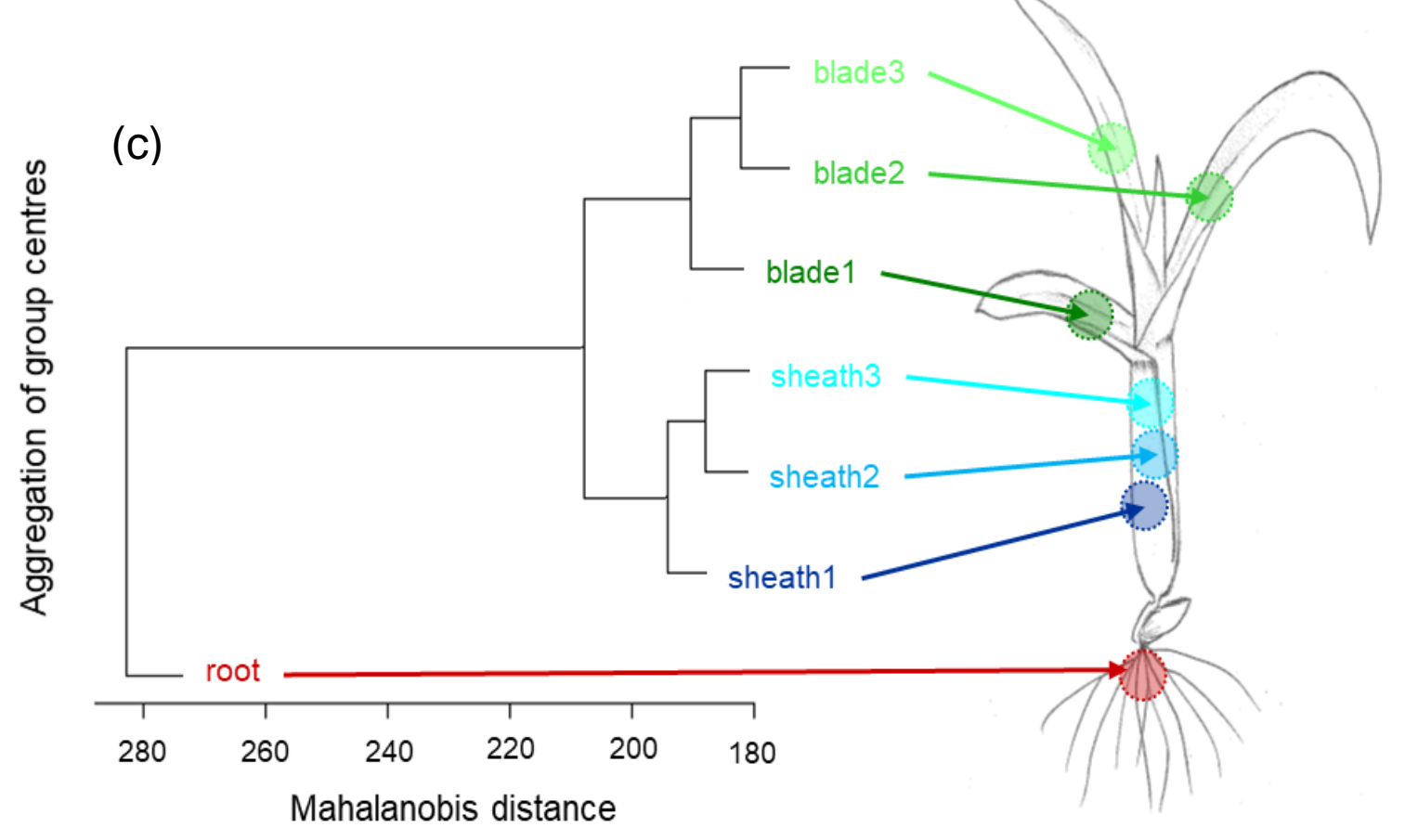

Figure 1: Analysis of the differentiation of DNA methylation profiles of barley roots, leaf sheaths and leaf blades. (a) Scatter plot of the first two discriminant factors of the Principal Component - Linear Discriminant Analysis (PC-LDA) (DF1 and DF2) using 913,697 ms-GBS markers generated from genomic DNA of roots, leaf sheaths and leaf blades, collected from 25 barley plants at the three-leaf stage (21 days after sowing), comprising five varieties (Barque 73, Flagship, Hindmarsh, Schooner and Yarra). (b) Three-dimensional plot of the first three discriminant factors of the PC-LDA of the same ms-GBS data. (c) Hierarchical cluster of the distances between sample group centres, based on Mahalanobis distance. Blade 1-3 and sheath 1-3 indicate the rank of the organ type, first, second and third leaf of seedlings, respectively.

Table 2: Number of Differentially Methylated Markers in barley tissues of different ages. Differentially methylated markers (FDR <0.05) were obtained from 913,697 ms-GBS tags generated 
122

123

124

125

from genomic DNA of barley roots, leaf sheaths and leaf blades, collected from 25 plants at three-leaf stage (21 days after sowing) of five barley varieties (Barque 73, Flagship, Hindmarsh, Schooner and Yarra). Blade 1-3 and sheath 1-3 indicate the rank of the leave, first, second and third, respectively, on seedlings.

Blade 1 Blade 2 Blade 3 Sheath 1 Sheath 2 Sheath 3

\begin{tabular}{ccccccc}
\hline Blade 1 & - & & & & \\
Blade 2 & 0 & - & & & \\
Blade 3 & 0 & 0 & - & & & \\
Sheath 1 & 32 & 37 & 73 & - & \\
Sheath 2 & 29 & 36 & 40 & 0 & - & \\
Sheath 3 & 0 & 1 & 1 & 18 & 0 & - \\
\hline
\end{tabular}

126

127

128

129

130

131

132

133

134

135

136

137

138

Differentially methylated DNA markers between roots and leaves

DMMs between barley roots and leaves were obtained through comparison of the read count per million of tissue types, independently of genotypes. This comparison revealed substantial DMMs between both roots vs blades and roots vs. sheaths (Fig. 2a), and there were more DMMs between roots and blades (6510 DMMs, Fig. 2b) than between roots and sheaths (4116 DMMs, Fig. 2c). Of these markers, 3266 DMMs were present in both blades and sheaths when compared to roots, and their methylation changed consistently in the same direction in each comparison (Fig. 3a). The number of DMMs between roots and leaf blades increased with leaf-rank, whereas DMMs between roots and leaf sheaths did not show any relationship with rank (Fig. 2a). Tissue-specific DMMs were predominantly hypomethylated (95-98\%) in leaf parts (sheath or blade) compared to roots (Fig. 2a). This result was in line with the median of the fold-changes of DMMs, which indicated an overall DNA hypomethylation in leaves (Fig. 4a,b). From here on, DMMs consistently present in roots vs. sheaths and roots vs. blades will be designated as stable markers between roots and leaves. 
(a)

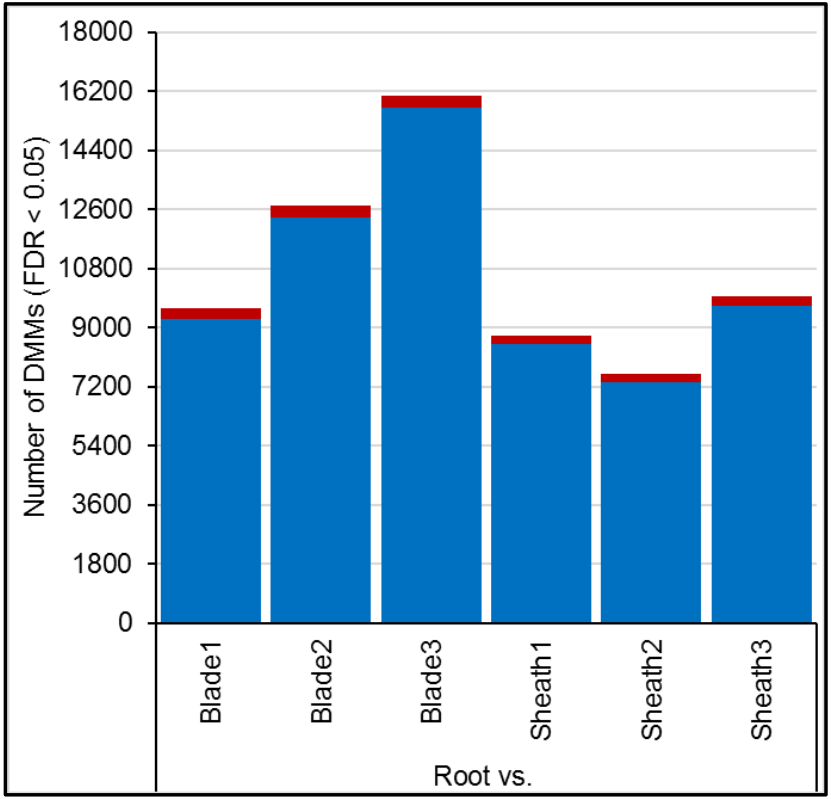

(d)

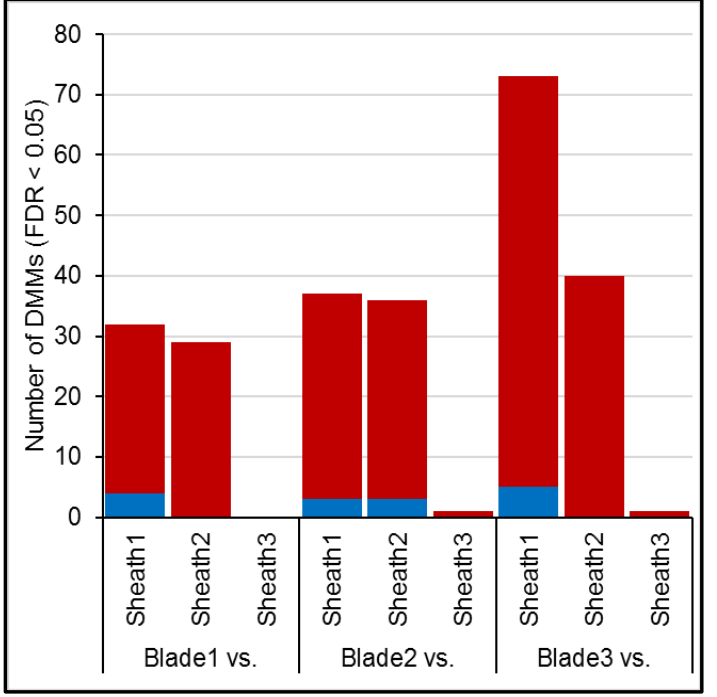

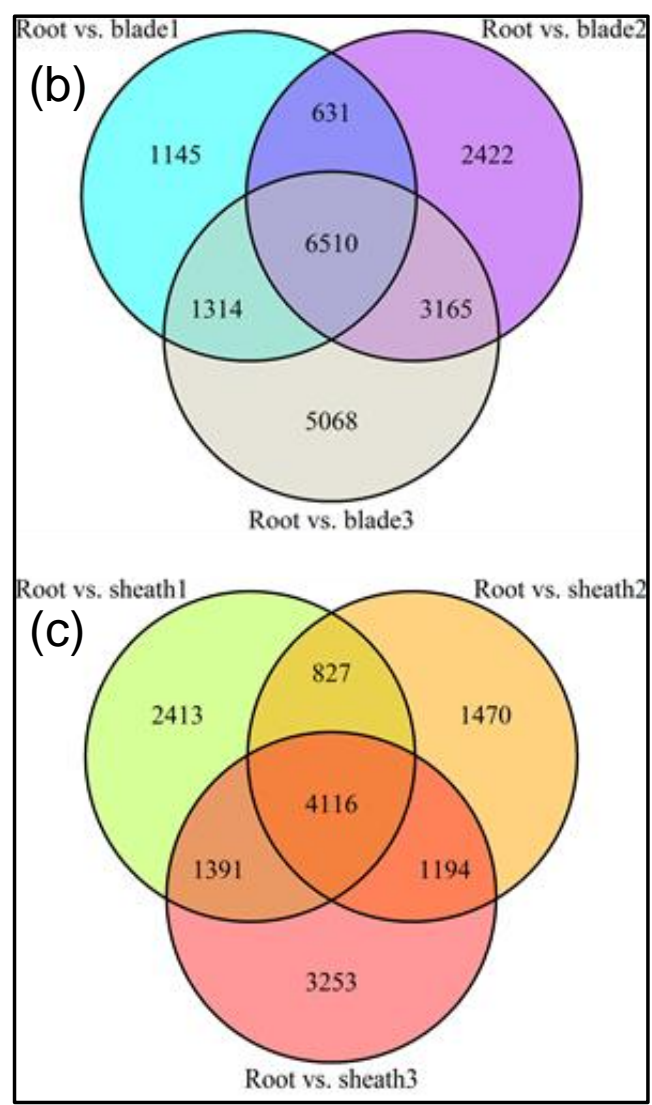

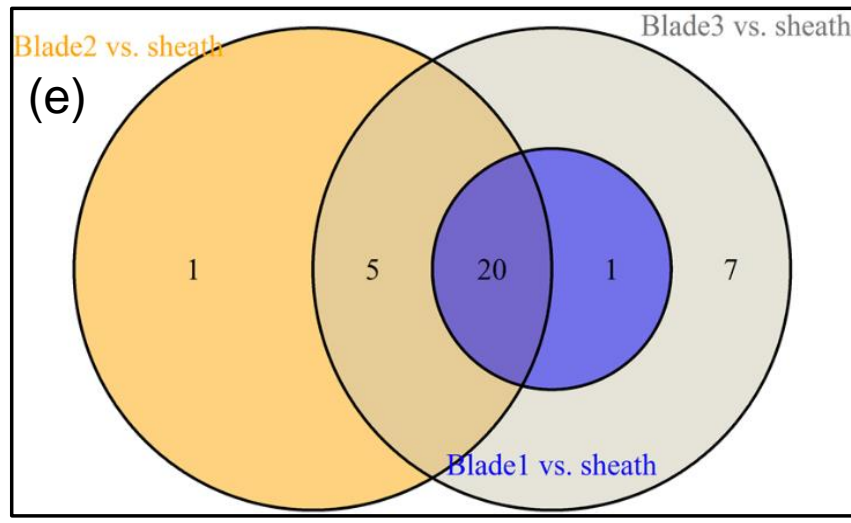

Figure 2: Analysis of the number of DMMs among three barley tissues. (a) Number of DMMs between roots and leaf blades (Root vs. blade) and roots and sheaths (Roots vs. sheaths). Histogram colour indicates whether the DMMs are hypomethylated (blue) or hypermethylated (red) in leaf parts compared to roots. (b-c) Venn diagram showing the number of DMMs stable between root and blade tissues (b) and between root and sheath tissues (c). (d) Number of DMMs from pairwise comparison between leaf blades 1-3 and sheaths 1-3. Histogram colour indicates whether the DMMs are hypomethylated (blue) or hypermethylated (red) in sheaths compared to blades. (e) Venn diagram showing the number of DMMs common in pairwise comparisons between leaf blades 1-3 and sheaths 1-2. Tissue samples were collected from seedlings at the three-leaf stage of five barley varieties grown in five replicates for 21 days after sowing. Blade 1-3 and sheath 1-3 indicate the rank of the organ type, first, second and third, respectively, on seedlings. DMMs were selected based on the significance of the false discovery rate, FDR, $<0.05$. DMMs present in both sheaths and blades when compared with roots, have been designated as markers between roots and leaves. 
154 155 156 157 158 159 160 161 162 163 164 (a)

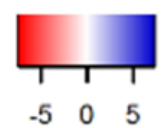

Fold change of DNA methylation

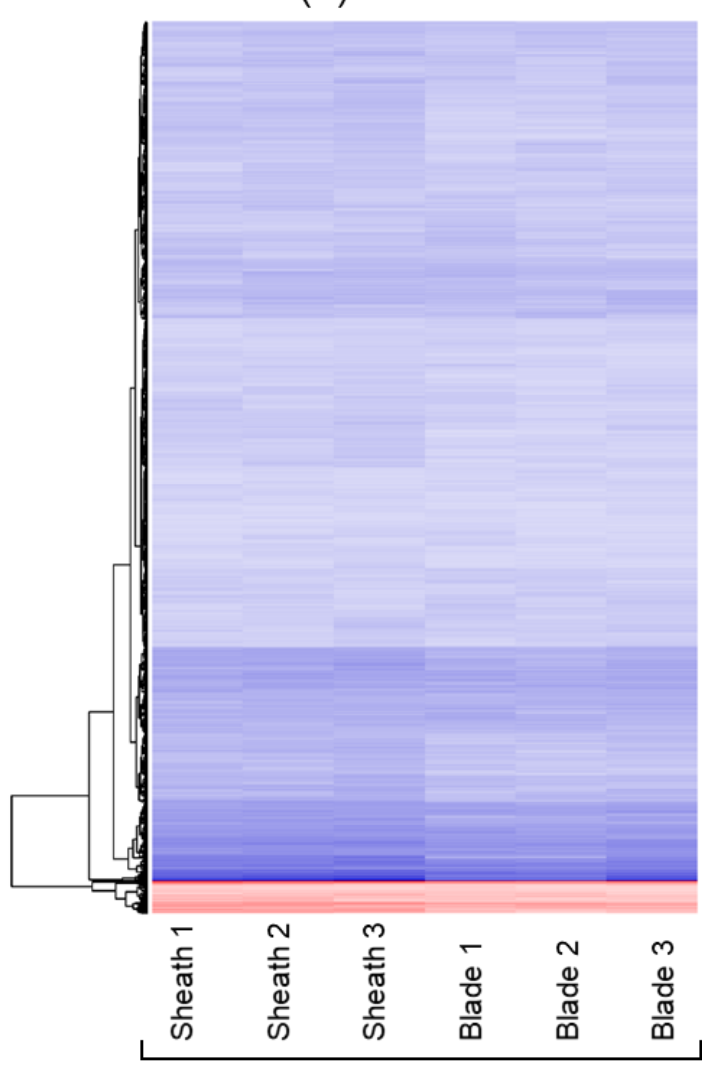

(b)
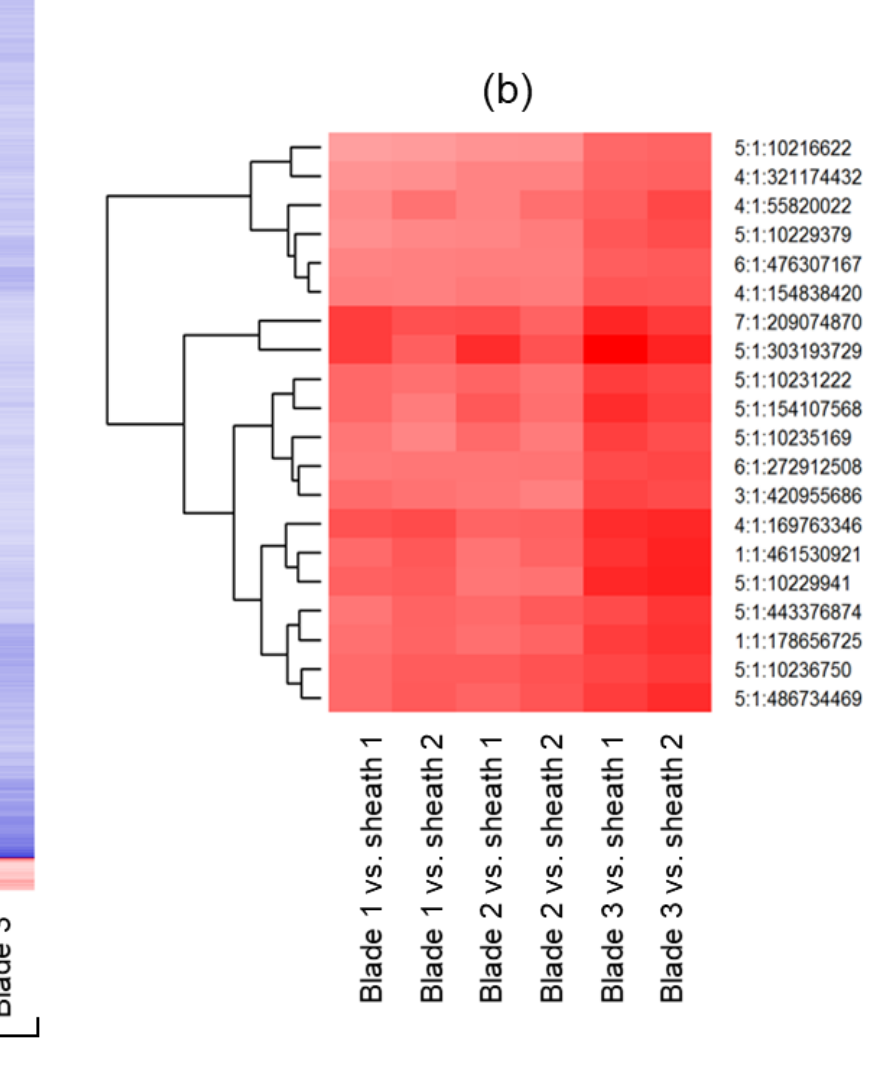

\section{5}

166

167

168

169

170

171

172

173

174

There was only a small number of DMMs between leaf blades and sheaths ( 0 to 73 DMMs, Table 2; Fig. 2d). These DMMs were basically between leaf blades and sheaths 1 and 2; and there was none between blade 1 and sheath 3 . There was only 1 DMM between sheath 3 and blades 2 and 3 (Table 2; Fig. 2d). Pairwise comparisons between blades 1-2 and sheaths 1-2 revealed 20 common DMMs, which were all hypermethylated in sheaths compared to blades (Fig. 2e and Fig. 4b). Half of the 20 common DMMs between blades and sheaths were located on chromosome $5 \mathrm{H}$. Furthermore, there were no DMMs in pairwise comparisons among blades 1-3 and among sheaths 1-3, except between sheath 1 and sheath 3 which had 18 DMMs (Table 2). However, comparing blades and sheaths of the same leaf rank showed 32 DMMs between blade 1 and sheath 1, 36 DMMs between blade 2 and sheath 2 and 1 DMM between blade 3 and sheath 3 .

Root vs.

Figure 3: Hierarchical clustering analysis of the DMMs. (a) the 3266 common DMMs between roots and all leaf parts (sheath 1-3, blade 1-3). The colours in the heat map indicate whether the DMM is hypomethylated (blue) or hypermethylated (red) in leaf parts compared to roots. (b) Hierarchical clustering of the 20 stable DMMs between blades and sheaths. In this heat map the red colour shows hypermethylation of DMMs in sheaths compared to blades. Blade and sheath samples were collected from seedlings at three-leaf stage of five barley varieties grown in five replicates for 21 days after sowing. Blade 1-3 and sheath 1-3 indicate the rank of the leaf on seedlings, first, second and third, respectively. The first number of the marker label on the y axis indicates the chromosome number on which the marker is located. 
(a)

\section{Distribution of tissue-specific DMMs around genes}

Relatively few of the tissue-specific DMMs were located around gene exons. Indeed, of the 3266 stable DMMs between root and leaf samples, only $60(1.8 \%)$ were located within $5 \mathrm{~Kb}$ of a gene, including 21 overlaps with genes and 39 DMMs that were spread within $5 \mathrm{~Kb}$ upstream and downstream of genes (Fig. 5a). Apart from the absence of DMMs within $1 \mathrm{~Kb}$ upstream of transcription start sites, there was no obvious tissue-specific DMM distribution pattern around the

Figure 4: Directionality of the methylation in tissue-specific DNA methylation markers. (a) Boxplots showing the spread of the fold-change of read counts of DMMs between blades and sheaths, roots and blades, and roots and sheaths. (b) Detail of boxplots, highlighting the median of methylation foldchange of all samples in each comparison. The fold-change of DNA methylation was estimated by computing $2^{(\log 2 \mathrm{FC})}$, with $\log 2 \mathrm{FC}=\operatorname{logarithm} 2$ of fold-change in read counts per DMM between pairwise comparisons of tissues collected from three-leaf stage barley seedlings. Leaf blades were the reference state for blade-sheath comparison, whereas roots were the reference for root-blade and rootsheath comparisons. Negative and positive values on the y axis indicate respectively, hypermethylation and hypomethylation of the tissue that is compared to the reference. genes (Fig. 5a). The same assessment process showed that, as with common DMMs, only a small proportion of blade-specific DMMs (44 of 3246, 1.3\%) was positioned close to a gene (Fig. 5b). Of these, 15 DMMs overlapped with a gene transcript, whereas the remaining 29 DMMs were distributed within $5 \mathrm{~Kb}$ of the gene without any clear pattern (Fig. 5b), except that the number of DMMs located between 2 and $3 \mathrm{~Kb}$ bins was higher both upstream and downstream, than any other $1 \mathrm{~Kb}$ bin within the $5 \mathrm{~Kb}$ flanking regions (Fig. $5 \mathrm{~b}$ ). There were fewer sheath-specific methylation markers within $5 \mathrm{~Kb}$ from genes than blade-specific markers (13 of $2391 \mathrm{DMMs}, 0.5 \%$ ) (Fig. $5 \mathrm{c}$ ). The majority of these (10 out of $13 \mathrm{DMMs}$ ) were sited within $3 \mathrm{~Kb}$ of a gene, and no DMMs were present 3-5 $\mathrm{Kb}$ from transcription margins (Fig. 5c). Of 37 gene-body DMMs detected across all comparisons (Fig. 5a-c), 27 overlapped with an exon and the remaining 10 markers were in intergenic regions, 70 to 604 bp upstream of exons, except 1 DMM, which was 62 bp downstream an exon (Table S1). 

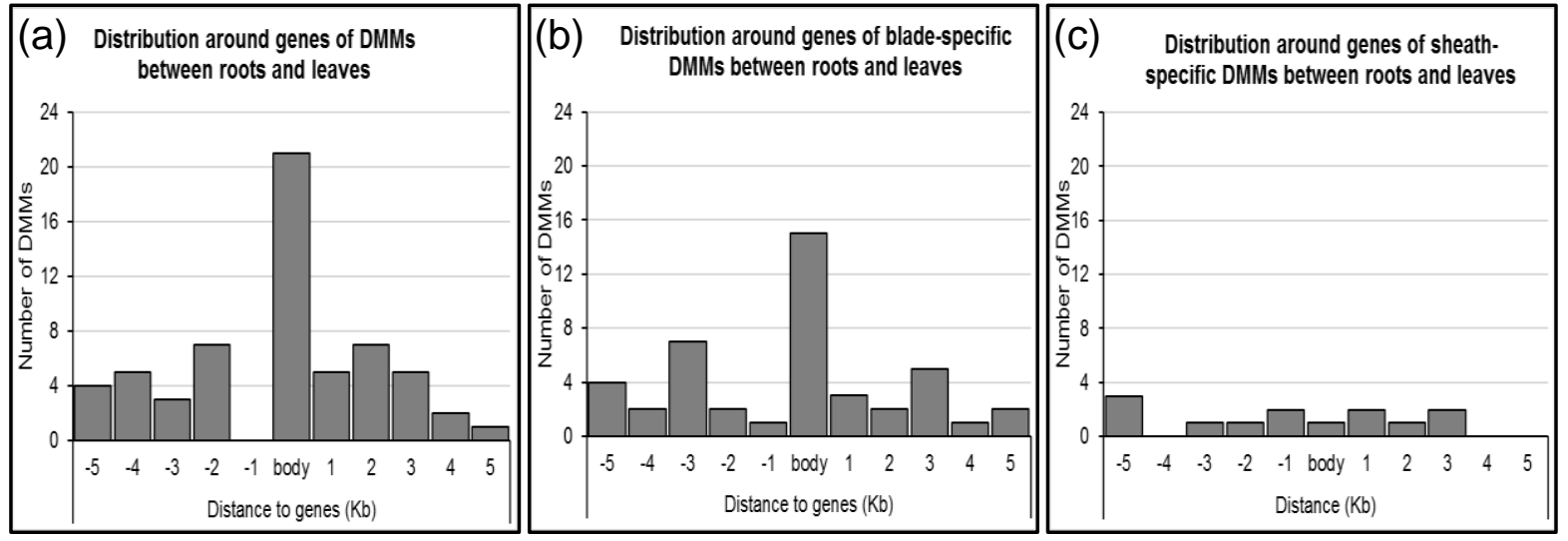

Figure 5: Distribution of tissue-specific differentially methylated markers (DMMs) around genes. (a) DMMs between roots and leaves, present in both blades and sheaths as in Figure 2b-c; (b) Bladespecific DMMs between roots and leaves and (c) Sheath-specific DMMs between roots and leaves. The $y$ axis indicates the distance to genes in kilo base pairs $(\mathrm{Kb})$ on both flanking regions. Negative and positive values indicate upstream and downstream of genes, respectively. DMMs overlapping with genes are considered as changes in gene-body methylation (body). The $\mathrm{x}$ axis shows the number of DMMs per $1 \mathrm{~Kb}$ window.

Distribution of tissue-specific DMMs near repeat regions

Many more tissue-specific DMMs were detected near repeats than near genes. The DMMs around repeat regions (as defined in the Ensembl database (http://plants.ensembl.org/biomart/martview/) were concentrated either within the repeats or within $1 \mathrm{~Kb}$ of their margins (Fig. 6a). A similar distribution pattern was obtained with both blade-specific and sheath-specific DMMs when contrasted with roots, with more DMMs overlapping with the repeats themselves than in the $1 \mathrm{~Kb}$ stretches flanking their margins (Fig. 6b,c). The few markers that were differentially methylated between blades and sheaths (20 DMMs in total) were all located within $1 \mathrm{~Kb}$ of a repeat (Fig. 6d). Therefore, stable tissue-specific DMMs appeared to occur preferentially within repeats and $1 \mathrm{~Kb}$ flanking regions, with higher frequency within $1 \mathrm{~Kb}$ downstream than within $1 \mathrm{~Kb}$ upstream, regardless of tissue types (Fig. 6a-d). 

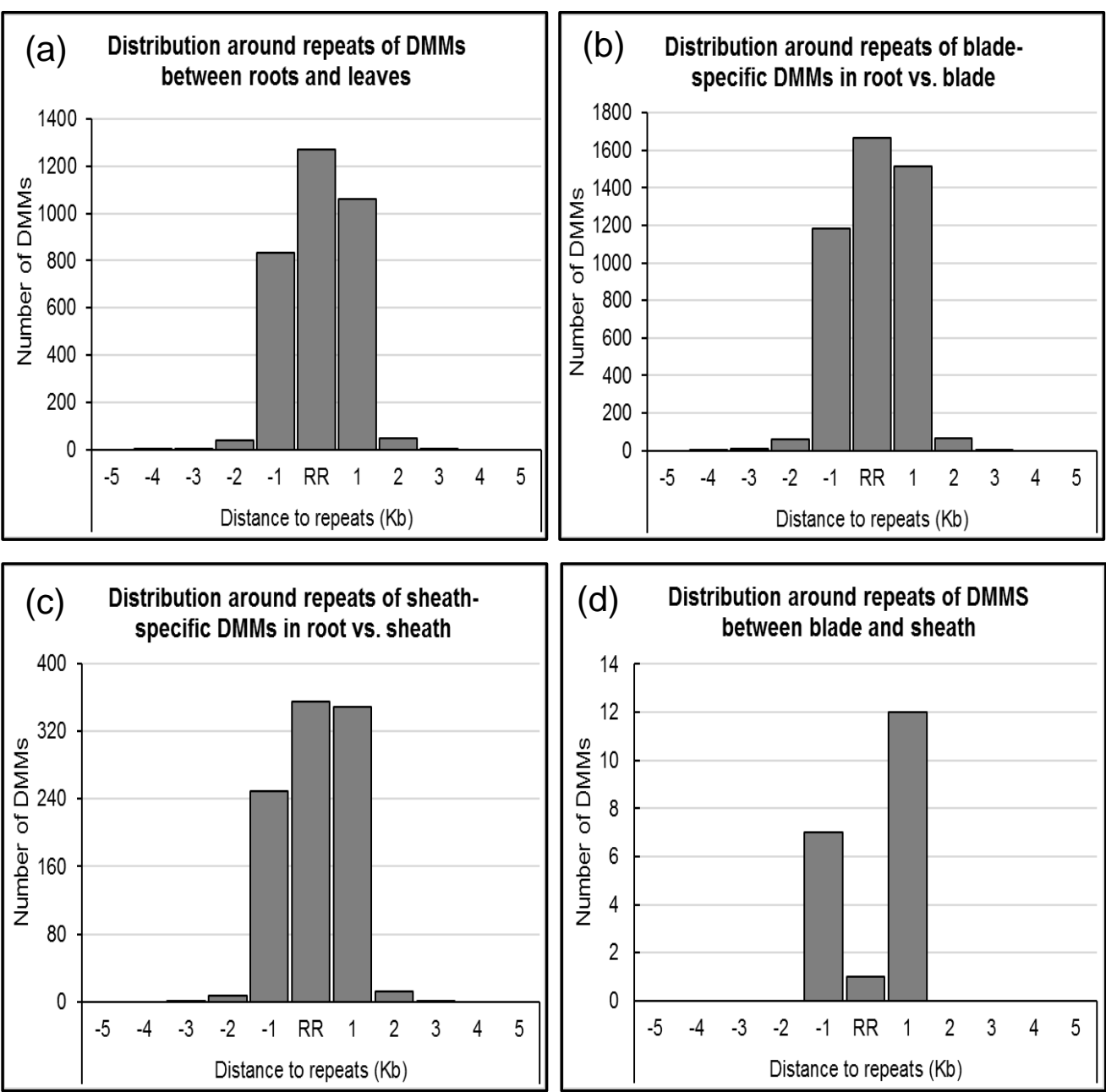

Figure 6: Distribution of tissue-specific differentially methylated markers (DMMs) around repeats. (a) DMMs between roots and leaves, present in both blades and sheaths as in Figure 2bc; (b) bladespecific DMMs between roots and leaves; and (c) sheath-specific DMMs between roots and leaves; (D) DMMs between blades and sheaths. The $\mathrm{x}$ axis indicates the distance to repeats in kilo base pairs $(\mathrm{Kb})$ on both flanking regions. Negative and positive values indicate upstream and downstream repeat regions, respectively. RR, repeat regions. The y axis shows the number of DMMs per $1 \mathrm{~Kb}$ window.

Distribution of genes around differentially methylated (DM) repeats

To investigate a possible interaction between differentially methylated (DM) repeats and genes, the distance of genes from DM repeats between root and leaf samples was evaluated. In this way, we found 105 genes near repeats (up to $5 \mathrm{~Kb}$ either side), of which 37 overlapped with a repeat and the remaining genes were scattered up- and downstream from the repeat (Fig. 7). The number of DM repeats surrounded by genes thus represented only a tiny proportion of the total repeats that were differentially methylated between roots and leaves (105 out of 3266 DM repeats, 3.21\%). Genes around DM repeats are listed in Table S2. About half of these genes near DM repeats (52 of 105 genes) were also differentially methylated, whereas the remainder ( 53 genes) were not. 


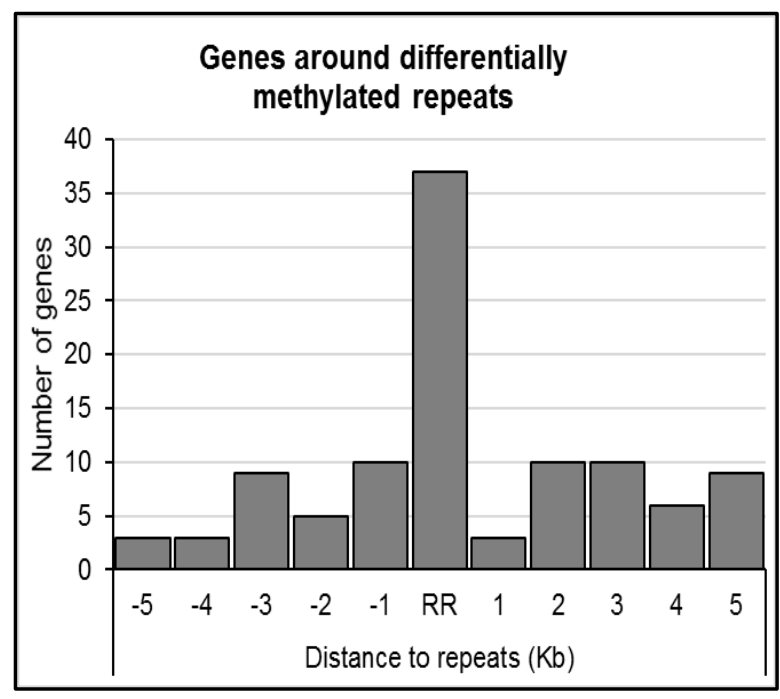

Figure 7: Distribution of genes around differentially methylated repeat regions. The $\mathrm{x}$ axis indicates the distance to repeats in kilo base pairs $(\mathrm{Kb})$ on both flanking regions. Negative and positive values indicate upstream and downstream repeat regions, respectively. RR, repeat regions. The y axis shows the number of genes per $1 \mathrm{~Kb}$ window.

Gene ontology of differentially methylated genes

The 107 genes differentially methylated between root and leaf samples were described by 213 GO terms within the three main categories; "biological process", "cellular component" and "molecular function", of which 121 GO terms were shared by both leaf parts, 88 were specific to blades and 4 to sheaths (Table 3). Thus, it appeared that although most functions were shared by both parts, leaf-blades carried a greater diversity of specific functions than did the leaf blades.

The GO analysis provided a picture of the role of DM genes in barley physiology and metabolism. Genes that were differentially hypermethylated in leaves compared to roots related to GO terms predominantly represented by "organonitrogen compound metabolism" and "generation of precursor metabolites and energy" (Fig. 8a, Table S3-4). The top five GO term representatives of hypomethylated genes in leaves relative to roots were; "organophosphate biosynthesis", "peptide metabolism", "monovalent inorganic cation transport", "electron transport chain", and "generation of precursor metabolites and energy". Similarly, it is also worth mentioning that photosynthesisassociated GO terms (GO:0015979) were enriched among genes hypomethylated in leaf tissues. Also, cellular components that set apart roots and leaves concerned chloroplast thylakoid (GO:0009534 and GO:0009579) and cytochrome complex (GO:0070069), which are part of the photosynthetic machinery, and were all derived from genes hypomethylated in leaves (Figure S1a, Supplemental Data 3.S3). Furthermore, there was a high frequency of the GO term "plastid" (GO:0009536), which was enriched in both hypermethylated and hypomethylated genes (Figure S1b-e, Supplemental Data 3.S3-4).

Some of the GO terms from differentially hypomethylated genes in leaves, were related to molecular functions represented by; "tetrapyrrole binding", "monovalent inorganic cation transmembrane transporter activity", "transition metal ion binding", "hydrolase activity" and "quinone activity" (Fig. S2a, Table S2). While no GO term belonging to molecular function was enriched by DM genes specific to sheaths, blade-specific DM genes enriched GO terms around "monovalent inorganic cation transmembrane transporter activity", "ATPase activity coupled", and "adenyl-ribonucleotide binding" (Fig. S2b, Table S3). 
273

274

275

276 hypo refer to hypermethylation and hypomethylation in roots compared with the other tissue (blade and sheath, respectively). GO terms were selected based on difference between their frequency in DM genes and non-DM genes, with adjusted P-value $<0.01$.

\begin{tabular}{cccccccc}
\cline { 2 - 7 } & \multicolumn{3}{c}{ DM genes } & \multicolumn{3}{c}{ GO terms } \\
\cline { 2 - 7 } & Hyper & Hypo & ${ }^{*}$ Total & Hyper & Hypo & ${ }^{*}$ Total \\
\hline Root vs. blade + sheath & 10 & 51 & 61 & 23 & 100 & 123 \\
Root vs. blade specific & 3 & 41 & 44 & 3 & 85 & 88 \\
Root vs. sheath specific & 1 & 1 & 2 & 2 & 2 & 4 \\
$\quad$ *Total & 14 & 92 & 107 & 28 & 187 & 215
\end{tabular}

*Totals may include duplicates, since the same gene can be both hypo- and hypermethylated, and the same GO term may be present in both groups. 

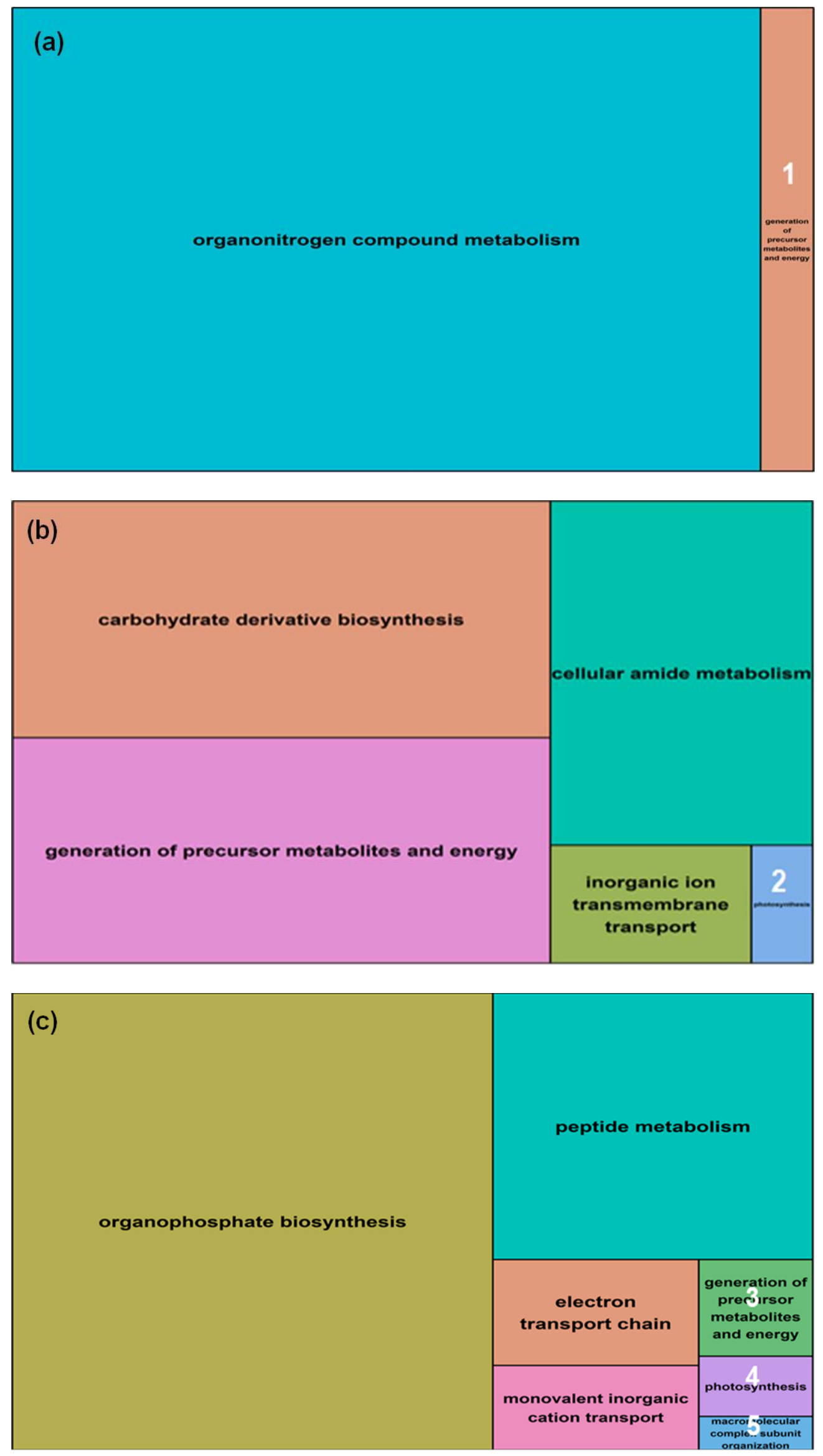
Figure 8: Summary treemaps of GO (gene ontology) term representatives for the category "biological process" obtained from differentially methylated genes between roots and leaves. (a) Representatives of GO terms enriched by common differentially hypermethylated genes in blades and sheaths; $1=$ generation of precursor metabolites and energy; (b) Representatives of GO terms enriched by common differentially hypomethylated genes in blades and sheaths; $2=$ photosynthesis; (c) Representatives of GO terms enriched by blade-specific differentially hypomethylated genes; $3=$ generation of precursor metabolites and energy, 4 = photosynthesis, 5 = macromolecular complex subunit. Treemaps were constructed using $\mathrm{R}$ scripts produced by the REVIGO server (http://revigo.irb.hr/). The detailed list of terms in the background of GO representatives is provided in the Table S2-4.

\section{Gene ontology of genes near differentially methylated repeats}

Since some of the genes around DM repeats were also differentially methylated and analysed as such for GO enrichment above, only non-DM genes around DM repeats (53 of 105) were used for further GO analysis. This analysis generated 97 significantly enriched GO terms in the three categories; "biological process", "molecular function" and "cellular component". Strikingly, most of the GO terms enriched by non-DM genes around DM repeats (93 of 97 GO terms, 95.88\%) were also enriched in DM genes.

The top GO term representatives in the "biological process" category were; "organophosphate biosynthesis", "peptide metabolism", electron transport chain", "monovalent inorganic cation transport", "generation of metabolites and energy" and "photosynthesis" (Fig. 9a). In the GO category "cellular component", the GO term "plastid" predominated, along with "thylakoid" and "thylakoid membrane" (Fig. 9b). GO terms enriched in the category "molecular function" belonged to the following five sub-categories, in order of importance; "tetrapyrrole binding", "cation transmembrane transporter activity", "transition metal ion binding", "hydrolase activity" and “NADH dehydrogenase (quinone) activity" (Fig. 9c). 

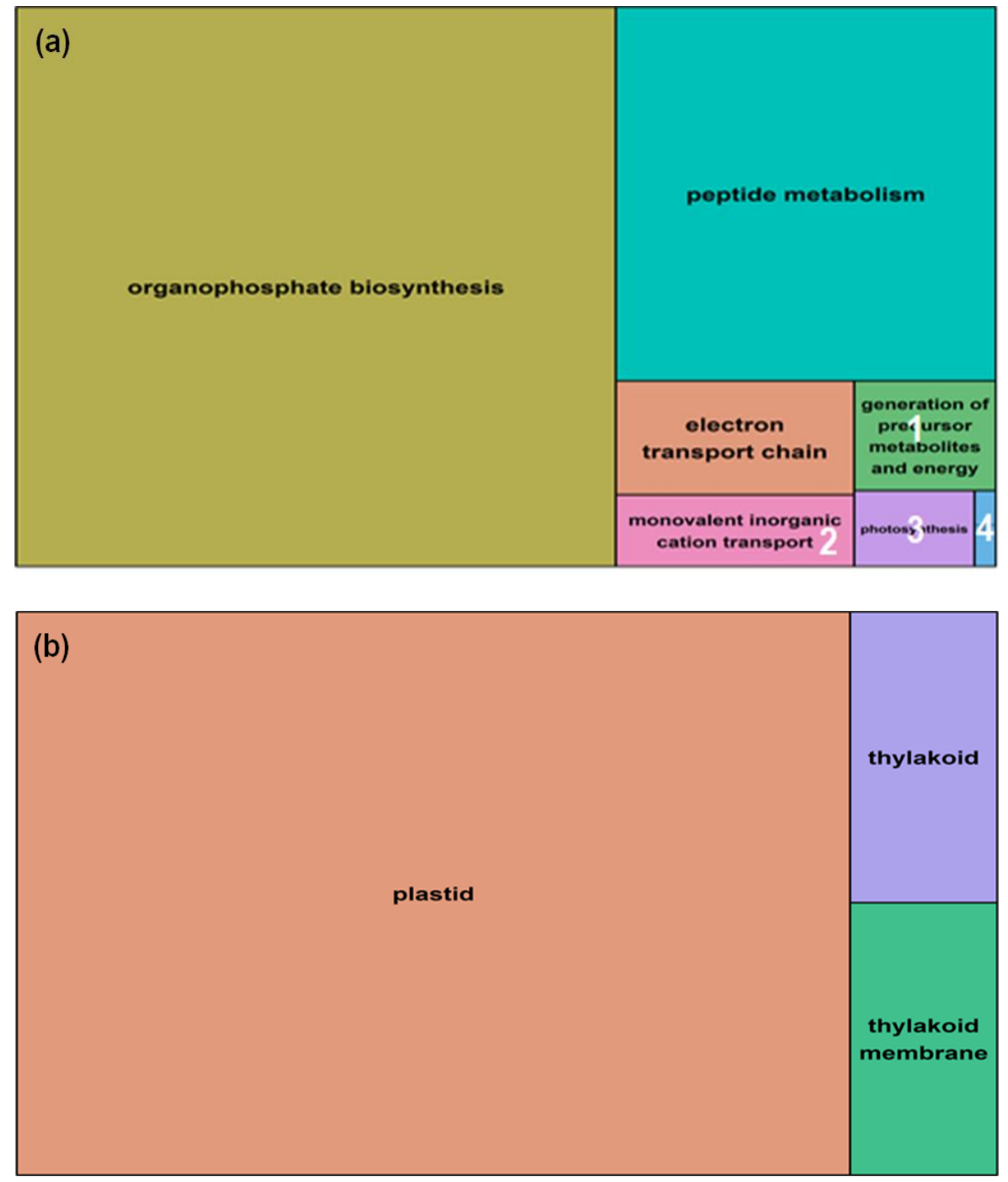

\section{(c)}

tetrapyrrole binding

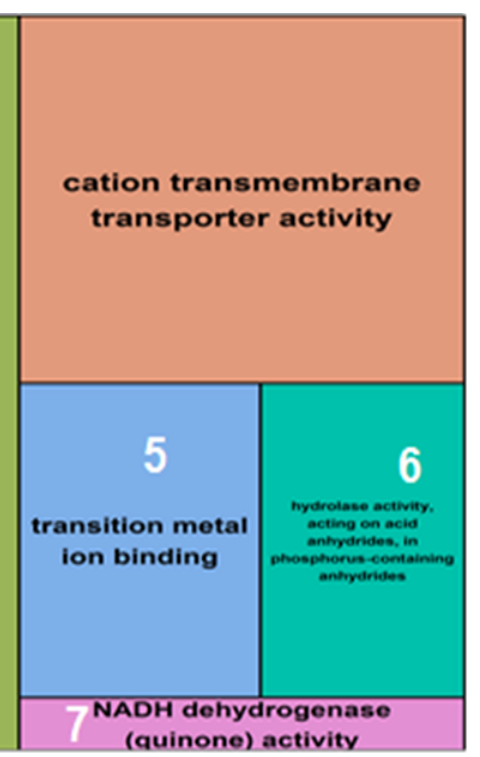


Figure 9: Representative GO enrichment summary treemaps obtained from genes near DM repeats between roots and leaves. (a) Representatives of GO terms enriched in the category "biological process"; 1 = generation of precursor metabolites and energy; 2 = monovalent inorganic cation transport; 3 = photosynthesis; 4 = macromolecular complex subunit organisation; (b) Representatives of GO terms enriched in the category "cellular component"; (c) Representatives of GO terms enriched in the category "molecular function"; $5=$ transition metal ion binding; $6=$ hydrolase activity, acting on acid anhydrides, in phosphorus containing anhydrides; $7=\mathrm{NADH}$ dehydrogenase (quinone) activity. Treemaps were constructed using $\mathrm{R}$ scripts produced by the REVIGO server (http://revigo.irb.hr/).

\section{Discussion}

\section{Extensive epigenetic differentiation between roots and leaves}

In this study, we detected large numbers of DDMs between roots and leaves that were conserved across diverse array of barley genotypes, and so were deemed far more likely to be organ-specific than genotype-dependent. Of these, hypomethylation of the ${ }^{\mathrm{m} C C G G}$ motif predominated in leaves (Fig. 2b,c, Fig. 3b and Fig. 4a). More surprisingly, we also detected similarly conserved DMMs between leaf-blades and leaf-sheaths (Fig. 2e and Fig. 4b). The number of conserved DMMs between blades and sheaths (20 DMMs), all hypermethylated in sheaths, was relatively consistent with the closeness of these structures in position and function. These findings are broadly congruent with previous studies, which reported differential DNA methylation between variable tissues (e.g. endosperm, pollen, leaves, roots) in diverse plant species [7-10], but additionally hint that the developmental closeness of structures being compared may also be reflected in the distinctiveness of their methylation profiles. However, controversy over the extent and validity of organ-specific DMMs [9,10,21-23] could cast doubt over their utility for organ diagnosis or as a tool to gain greater insight into the genes responsible for organ development/identity. Here, we sought to mitigate against the possibility of type I errors in DMM assignment through the unprecedented use of five diverse varieties and five biological replicates of each variety in the identification of these marks. In contrast to our findings, previous workers have reported little difference in the methylation levels of both ${ }^{\mathrm{m} C G}$ and ${ }^{\mathrm{m}} \mathrm{CHG}$ motifs between roots and leaves in Arabidopsis [9] and sorghum [10]. Further, no significant difference was detected at all for ${ }^{\mathrm{m}} \mathrm{CG}$ and ${ }^{\mathrm{m}} \mathrm{CHG}$ methylation levels between tissues in cotton [29]. These divergences may simply reflect genuine biological differences between taxonomic groups. However, it is also important to recognise that such differences may also arise from the approach used to identify organ-specific DMMs. Variability in the techniques used to assess plant methylation profiles may introduce different forms of bias and preclude or complicate comparison among studies. DMM detection can be influenced by factors such as 1) the genome coverage of the methylation profiling method (low coverage methods such as MSAP are likely to miss many markers [7], and 2) the data analysis approach used, which can compare either global methylation levels (e.g. percent methylation [9] or methylated loci (e.g. DMMs [30]. We contend that relying solely on global methylation levels can be misleading in comparing tissue profiles, because similar methylation levels may show completely different patterns and so vital information content is lost.

The current study revealed that tissue-specific DNA methylation occurred abundantly in the mCHG context (at least ${ }^{\mathrm{m} C C G G s) ~(F i g . ~ 2 a-c) . ~ T h i s ~ c o n c u r s ~ w i t h ~ r e p o r t s ~ o f ~ t h e ~ C H G ~ c o n t e x t ~ s i m i l a r l y ~}$ dominating differential DNA methylation between organs in Brachypodium distachyon [8] and sorghum [10]. Although tissue-specific methylation also occurs in other cytosine contexts [10], our results and other studies $[10,22]$ suggest that ${ }^{\mathrm{C}}$ CCGG is a primary motif of epigenetic distinctiveness of plant organs. Additionally, while tissue-specific DMMs were mostly hypomethylated in leaves compared to roots in the present study (Fig. 3b), in Arabidopsis, Widman et al. [9] found that hypermethylation prevailed in leaves compared with roots. This apparent contradiction in the 
354

355

356

357

358

359

360

361

362

363

364

365

366

367

368

369

370

371

372

373

374

375

376

377

378

379

380

381

382

383

384

385

386

387

388

389

directionality of methylation in DMMs between roots and leaves may be a reflection a difference in the polarity of early divisions in the monocotyledonous barley and the dicotyledonous Arabidopsis embryos or else the methylation profiling method implemented.

\section{DNA methylation flux is tissue specific during barley seedlings development}

In addition to tissue-specificity of methylation profiles, one notable finding in the current study was that leaf cohorts exhibited a strong tendency to co-cluster. This suggests that the nature of methylation divergence between organs is not absolutely fixed and instead appears to change with developmental progression. This observation accords with previous reports that genome-wide methylation patterns are not static during plant development [31]. Additionally, a considerable portion of DMMs between roots and leaves was also specific to the leaf rank, due to the steady decrease in the number of DMMs between roots and leaf blades with the rank of the latter (Fig. 2a-c). In this case, therefore, the slow but progressive accumulation of additional methylation marks in the leaves increases their divergence from root profiles and enables the separation of leaf cohorts. However, the small number of DMMs distinguishing between leaf blades and leaf sheaths ran counter to this trend such that there were no DMMs capable of discrimination between these leaf parts among the oldest cohort studied (leaf 1) (Fig. 2d, Table 2). It seems intuitively improbable that older cohorts of leaves would simply lose differentiation between structurally distinct parts, especially if these marks had a functional role in defining function. Perhaps the most plausible biological explanation for the apparent erosion of divergence lies in the different chronological ages of the leaf cohorts that were sampled. Put simply, the third leaves were the least mature of the three cohorts collected and so it is entirely possible that the blade-sheath differential marks had yet to appear in these samples. Thus, it is important to consider the developmental and ageing progression chronology when assigning DMMs and that some organ- or structure-specific marks may only become organ-specific late in their development. Such late-emerging developmental DMMs should mean that the cumulative number of tissue-specific markers increases and so the organs or structures become more distinct, through leaf growth stages [32], each of which may carry a specific epigenetic profile. Certainly, others have noted that methylation profiles vary progressively as the organ develops $[3,33,34]$ before reaching, at maturity, a "default" methylome, which may be conserved across varieties [24]. These results suggest that, once leaves are differentiated and mature, they do not show significant differences in DNA methylation profiles, regardless of their rank of appearance. Additionally, the location of half of the 20 common DMMs between blades and sheaths on chromosome $5 \mathrm{H}$ implies that this chromosome carries loci important for blade and sheath identities.

Tissue-specific DNA methylation preferably occurs in repeat regions of the barley genome

One noteworthy feature of the organ-specific DMMs identified here is that far more were associated with repeat regions than in or around genes. Nevertheless, the fact that 27 DMMs overlapped with exons and 10 were located in introns (Table S1) contradicts previous claims that CHG methylation marks are exclusively restricted to repeat regions and intergenic regions $[20,21,35,36]$. The possible regulatory significance of such gene body CHG methylation marks requires further investigation [37]. However, it is already well-established that tissue-specific DMMs 
can influence gene expression by enhancing gene transcription [9] and alternative splicing [38] or through repression due to immediate proximity to transcription start site [39].

The predominance of DMMs around and within repeats leads us to speculate that they could play an important role in defining organ identity in barley, and accords with previous findings in Brachypodium distachyon [8]. This flux of DNA methylation patterns in repeats $[8,34,40]$ has been proposed to regulate [35] developmental shifts during plant growth and development [11,31]. Nevertheless, the association between DMMs in/around repeat regions and organ identity described here does not establish a causal link between the two. However, there are grounds for reasoning that this may be the case and that the possibility warrants further study. First, repeat regions were previously proposed to be involved in alternative promoters, a substantial proportion of which $(>40 \%)$ was reported to shape tissue differentiation [16]. Therefore, tissue-specific DMMs in repeats may contribute to alternative promoters, and thus determine organ identity. Second, differential gene expression between roots and leaves $[25,41]$ implies a firm regulatory system, including epigenetic mechanisms to guarantee tissue-specific cell development. Tissue-specific DMMs in repeats show that repeats are not that so-called "selfish parasites" of the genome [42], but can directly or indirectly affect tissue-specific gene expression $[34,43,44]$. Finally, it has been suggested that transposons coordinate splice variants, a genomic event that occurs in more than $60 \%$ of plant genes $[45,46]$, thus generating multiple mRNA transcripts from a single gene $[47,48]$. Many splice variants are tissuespecific [49], suggesting that it is entirely possible that tissue-specific DMMs in repeats affect alternative splicing and subsequent gene expression. Also, some DM genes might potentially be regulated simultaneously by their own methylation and that of repeats $[44,50]$, due to proximity with DM repeats.

\section{Tissue-specific DMMs target genes relevant to plant tissue function}

The widely noted observation that differential DNA methylation correlates with differential gene expression [10,14,51], led us to perform ontology analysis on DM genes and genes around DM repeats in the plant tissues. We reasoned that if a significant proportion of these marks were indeed regulatory, then their Gene Ontology classification profiles should broadly match those reported previously for these organs by transcript analysis. Our findings supported this tenet, with marked similarities noted between the overall GO classifications among DM-associated genes found here and those previously associated with expression divergence between roots and leaves. For instance, photosynthesis-associated GO terms (chloroplast thylakoid and cytochrome complex) were enriched in genes that were hypomethylated in leaves, which host photosynthesis (Simpson et al., 1986). Similarly, genes involved in organonitrogen compound metabolism were hypomethylated in roots, and relate to processes occurring in roots, such as nitrogen assimilation [52,53]. The cellular component "plastid", known as tissue-specific in green plants [54], was highly enriched in DM genes.

\section{Conclusions}

This study has identified a series of DMMs that allow for the discrimination of leaf parts and roots in young barley plants. Considered collectively, our data illustrates that during tissue development, DNA methylation evolves to reach a default profile once the tissue is completely differentiated at maturity. It is possible that the plant organ formation and maturation is under at least partial control of DNA methylation changes. In addition, repeats could play an important role in tissue definition. Tissue specific mCCGG sites suggests that this context carries important factors of tissue differentiation. Expression analysis of tissue samples would perfectly demonstrate the role of tissue-specific DMMs in gene regulation. Nevertheless, mapping indexed markers generated from the ms-GBS with barley reference gene transcripts, allowed us to identify between tissues DM genes, which Ontology indicated that their tight correlation with expected tissue-specific functions is not coincidental.

\section{Materials and Methods}


Plant material and growth conditions

Five spring barley varieties (Barque 73, Flagship, Hindmarsh, Schooner and Yarra) were grown in potting mix comprising 50\% UC (University of California at Davis), 35\% coco-peat and 15\% clay/loam $\left(\mathrm{v} \mathrm{v}^{-1}\right)$ in $3.3 \mathrm{~L}$ pots, $17.5 \mathrm{~cm}$ deep, free-draining and placed on saucers. The experiment was conducted from 30 th January to $20^{\text {th }}$ February 2015 in a greenhouse at the Waite Campus, University

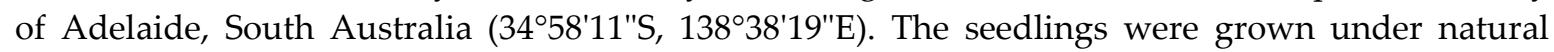
photoperiod while temperatures were set at $22^{\circ} \mathrm{C} / 15^{\circ} \mathrm{C}$ (day/night). The experiment consisted of five randomized blocks of five varieties ( 25 seedlings per block). Pots were watered to weight every 2 days to a gravimetric water content of $16.8 \%\left(\mathrm{w} \mathrm{w}^{-1}\right)(0.8 \times$ field capacity) [55] until sampling 21 days after sowing, when seedlings were at three-leaf stage (Zadok stage 13 [56]). Blades and sheaths of leaves 1-3 were sampled separately. Leaves 1 and 2 were fully expanded prior to sampling, whilst leaf 3 had just completed growth. About $50 \mathrm{mg}$ of plant material was cut from the middle section of each leaf blade and each leaf sheath and snap frozen in liquid nitrogen in $2 \mathrm{ml}$ micro tubes. Roots were cut from the seedlings and washed using tap water to remove soil particles, then blotted dry with paper towels before sampling $50 \mathrm{mg}$ of root tissue. Root samples were also frozen in liquid nitrogen, and then all samples were stored at $-80^{\circ} \mathrm{C}$ until DNA extraction.

\section{DNA isolation}

Prior to DNA extraction, frozen plant material was homogenized in a bead beater (2010Geno/Grinder, SPEX SamplePrep ${ }^{\circledR}$, USA). DNA isolation was performed from pulverised plant samples using a Qiagen DNeasy kit and following the manufacturer's instructions. DNA samples were quantified using a NanoDrop ${ }^{\circledR} 1000$ Spectrophotometer (V 3.8.1, ThermoFisher Scientific Inc.; Australia) and concentrations were standardized to $10 \mathrm{ng}^{\mathrm{l}^{-1}}$ for subsequent library preparation.

\section{Methylation Sensitive genotyping by sequencing (ms-GBS)}

The ms-GBS was performed using a modified version [30,57] of the original GBS technique [58]. Genomic DNA was digested using the combination of a methylation-insensitive rare cutter, EcoRI (GAATTC), and a frequent and methylation-sensitive cutter, MspI (CCGG). Each sample of DNA was digested in a reaction volume of $20 \mu \mathrm{l}$ containing $2 \mu \mathrm{l}$ of NEB Smartcut buffer, $8 \mathrm{U}$ of HF-EcoRI (High-Fidelity) and $8 \mathrm{U}$ of MspI (New England BioLabs, Australia). The reaction was performed in a BioRad 100 thermocycler at $37^{\circ} \mathrm{C}$ for 2 hours, followed by enzyme inactivation at $65^{\circ} \mathrm{C}$ for $10 \mathrm{~min}$.

Then, the ligation of adapters to individual samples was achieved in the same plates by adding 0.1 pmol of the respective barcoded adapters with an MspI cut site overhang, 15 pmol of the common $\mathrm{Y}$ adapter with an EcoRI cut site overhang, $200 \mathrm{U}$ of T4 Ligase and T4 Ligase buffer (New England BioLabs, Australia) in a total volume of $40 \mu \mathrm{l}$. Ligation was carried out at $24^{\circ} \mathrm{C}$ for 2 hours followed by an enzyme inactivation step at $65^{\circ} \mathrm{C}$ for $10 \mathrm{~min}$.

DNA samples were allocated to plates, 81 samples each, including the negative control, water. Prior to pooling plate samples into a single 81-plex library, the ligation products were individually cleaned up to remove excess adapters using an Agencourt AMPure XP purification system (Beckman Coulter, Australia) at a ratio of 0.85 (AMPure magnetic beads/ligation product), following the manufacturer's instructions. Individual GBS libraries were produced by pooling $25 \mathrm{ng}$ of DNA from each sample. Each constructed library was then amplified in eight separate PCR (25 $\mu$ l each) containing $10 \mu \mathrm{l}$ of library DNA, $5 \mu \mathrm{l}$ of $5 \times$ Q 5 high fidelity buffer, $0.25 \mu$ l polymerase Q5 high fidelity, $1 \mu \mathrm{l}$ each of Forward and Reverse common primers at $10 \mu \mathrm{M}, 0.5 \mu \mathrm{l}$ of $10 \mu \mathrm{M}$ dNTP and $7.25 \mu \mathrm{l}$ of sterile pure water. PCR amplification was performed in a BioRad T100 thermocycler, consisting of DNA denaturation at $98^{\circ} \mathrm{C}(30 \mathrm{~s})$ and ten cycles of $98^{\circ} \mathrm{C}(30 \mathrm{~s}), 62^{\circ} \mathrm{C}(20 \mathrm{~s})$ and $72^{\circ} \mathrm{C}(30 \mathrm{~s})$, followed by $72^{\circ} \mathrm{C}$ for $5 \mathrm{~min}$. PCR products were next pooled to reconstitute libraries. DNA fragments between 200 and 350 bp in size were captured using AMPure XP magnetic beads following the manufacturer's instructions. Bead-captured fragments were eluted in $35 \mu \mathrm{l}$ of water, of which $30 \mu \mathrm{l}$ were collected in a new labelled microtube. Libraries were next paired-end sequenced in an Illumina HiSeq 2500 (Illumina Inc., USA) at the Australian Genome Research Facility (AGRF, Melbourne node, Australia). 
Principal component - linear discriminant analysis

Grouping of organ type samples was explored by performing a principal component - linear discriminant analysis (PC-LDA) and a hierarchical cluster analysis using the R package FIEmspro 1.10 [28]. To visualise the results, we performed a scatter plot of the first two discriminant factors (DFs), a 3D plot using the first three DFs and a hierarchical cluster tree based on Mahalanobis distance [27].

\section{Detection of DMMs in barley}

Differentially methylated DNA was assessed in ${ }^{m}$ CCGG motifs (recognised by MspI), between barley leaf parts (blade and sheath) and roots. To do so, samples were grouped according to organ type (root, blade and sheath) regardless of the genotype of origin, making 25 samples per organ. This approach aimed to minimise genotype-dependent methylation markers. DMMs were identified using the package, $m s g b s R$, developed by Mayne et al. [59]. DMMs were selected based on Bonferroni adjusted P-values with a threshold of $0.05[60,61]$. The significance of the marker also fulfilled the condition that the read counts reached at least 1 CPM (count per million reads) and was present in at

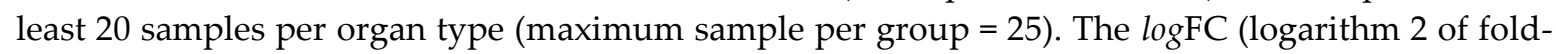
change) was computed to estimate the intensity and directionality of differential DNA methylation between tissues. Determining the directionality of DNA methylation uses the fold change as an inverse proxy for change in the methylation level. That is, higher methylation levels on a specific locus will reduce the number of $M s p I$ restriction products and therefore reduce the number of sequences generated for that locus [62].

\section{Distribution of DMMs around genomic features and gene ontology}

To test whether there was a relationship between tissue-specific DMMs and particular genomic features (e.g., genes and repeat regions as defined in Ensembl database (http://plants.ensembl.org/biomart/martview/), DMM distribution was assessed in the barley genome. Therefore, DMMs stable between tissues were mapped to the barley reference genome. Then, the number of DMMs within genomic features (repeats, genes, exons, UTRs and tRNA genes) and per $1 \mathrm{~Kb}$ bins within $5 \mathrm{~Kb}$ flanking regions [24,30] was tallied, using the shell module, bedtools 12.22.0 [63]. Furthermore, the functions of tissue-specific DM genes and genes near DM repeats were explored by performing gene ontology analysis. Genes within $5 \mathrm{~Kb}$ of a DMM were deemed differentially methylated genes (DM) genes, and were grouped in hypermethylated and hypomethylated genes per tissue. These genes were next used separately for Gene Ontology (GO) terms enrichment, using two R packages: GO.db and annotate [64,65]. Significant GO terms were selected based on Bonferroni adjusted P-values [60] at a significance threshold of 0.05 and a total GO enrichment of DM and non-DM genes at least equal to 10. To visualize the results of GO analysis, treemaps were generated in REVIGO [66], using default settings.

Supplementary Materials: The following are available online at www.mdpi.com/link, Figure S1: Summary treemaps for GO category “cellular components" from DM genes between roots and leaves. Figure S2: Summary treemaps for GO category "molecular function" from DM genes between roots and leaves. Table S1: List of differentially methylated exons. Table S2: List of GO terms enriched by differentially methylated genes between roots and leaves. Table S3: List of GO terms enriched by differentially methylated genes between roots and leaves and specific to blades. Table S4: List of GO terms enriched by differentially methylated genes between roots and leaves and specific to sheaths.

Acknowledgments: The authors are grateful to the Australian Agency for International Development (AusAID) for supporting MK with an Australian Awards Scholarship. MJW was paid by the BBSRC (BBS/E/W/0012843C).

Author Contributions: M.K. conceived and performed the experiments, analysed the data and wrote the manuscript; B.J.M. performed ms-GBS data alignments; M.J.W., E.S.S., B.B., C.M.R.L. conceived the experiments and supervised the work. All authors read and commented on the manuscript.

\section{Conflicts of Interest: The authors declare that they have no conflicts of interest.}

\section{References}


1. Bird, A. Perceptions of epigenetics. Nature 2007, 447, 396-398.

2. Zilberman, D.; Henikoff, S. Genome-wide analysis of DNA methylation patterns. Development 2007, 134, 3959-3965.

3. Cokus, S.J.; Feng, S.; Zhang, X.; Chen, Z.; Merriman, B.; Haudenschild, C.D.; Pradhan, S.; Nelson, S.F.; Pellegrini, M.; Jacobsen, S.E. Shotgun bisulphite sequencing of the Arabidopsis genome reveals DNA methylation patterning. Nature 2008, 452, 215-219.

4. Bossdorf, O.; Arcuri, D.; Richards, C.; Pigliucci, M. Experimental alteration of DNA methylation affects the phenotypic plasticity of ecologically relevant traits in Arabidopsis thaliana. Evolutionary Ecology 2010, 24, 541553.

5. Finnegan, E.J.; Peacock, W.J.; Dennis, E.S. Reduced DNA methylation in Arabidopsis thaliana results in abnormal plant development. Proceedings of the National Academy of Sciences 1996, 93, 8449-8454.

6. Aceituno, F.F.; Moseyko, N.; Rhee, S.Y.; Gutiérrez, R.A. The rules of gene expression in plants: organ identity and gene body methylation are key factors for regulation of gene expression in Arabidopsis thaliana. BMC Genomics 2008, 9, 1-14.

7. Rodríguez López, C.M.; Wetten, A.C.; Wilkinson, M.J. Progressive erosion of genetic and epigenetic variation in callus-derived cocoa (Theobroma cacao) plants. New Phytologist 2010, 186, 856-868.

8. Roessler, K.; Takuno, S.; Gaut, B.S. CG methylation covaries with differential gene expression between Leaf and Floral Bud Tissues of Brachypodium distachyon. PLoS One 2016, 11, e0150002.

9. Widman, N.; Feng, S.; Jacobsen, S.E.; Pellegrini, M. Epigenetic differences between shoots and roots in Arabidopsis reveals tissue-specific regulation. Epigenetics 2014, 9, 236-242.

10. Zhang, M.; Xu, C.; von Wettstein, D.; Liu, B. Tissue-specific differences in cytosine methylation and their association with differential gene expression in sorghum. Plant Physiology 2011, 156, 1955-1966.

11. Ay, N.; Janack, B.; Humbeck, K. Epigenetic control of plant senescence and linked processes. Journal of Experimental Botany 2014, 65, 3875-3887.

12. Xiao, W.; Custard, K.D.; Brown, R.C.; Lemmon, B.E.; Harada, J.J.; Goldberg, R.B.; Fischer, R.L. DNA methylation is critical for Arabidopsis embryogenesis and seed viability. The Plant Cell 2006, 18, 805-814.

13. Cocciolone, S.M.; Chopra, S.; Flint-Garcia, S.A.; McMullen, M.D.; Peterson, T. Tissue-specific patterns of a maize Myb transcription factor are epigenetically regulated. The Plant Journal 2001, 27, 467-478.

14. Song, Q.-X.; Lu, X.; Li, Q.-T.; Chen, H.; Hu, X.-Y.; Ma, B.; Zhang, W.-K.; Chen, S.-Y.; Zhang, J.-S. Genomewide analysis of DNA methylation in soybean. Molecular Plant 2013, 6, 1961-1974.

15. Lafon-Placette, C.; Faivre-Rampant, P.; Delaunay, A.; Street, N.; Brignolas, F.; Maury, S. Methylome of DNase I sensitive chromatin in Populus trichocarpa shoot apical meristematic cells: a simplified approach revealing characteristics of gene-body DNA methylation in open chromatin state. New Phytologist 2013, 197, 416-430.

16. Batut, P.; Dobin, A.; Plessy, C.; Carninci, P.; Gingeras, T.R. High-fidelity promoter profiling reveals widespread alternative promoter usage and transposon-driven developmental gene expression. Genome Research 2013, 23, 169-180.

17. Maunakea, A.K.; Nagarajan, R.P.; Bilenky, M.; Ballinger, T.J.; D/'Souza, C.; Fouse, S.D.; Johnson, B.E.; Hong, C.; Nielsen, C.; Zhao, Y., et al. Conserved role of intragenic DNA methylation in regulating alternative promoters. Nature 2010, 466, 253-257.

18. Sørensen, M.B.; Müller, M.; Skerritt, J.; Simpson, D. Hordein promoter methylation and transcriptional activity in wild-type and mutant barley endosperm. Molecular and General Genetics 1996, 250, 750-760.

19. Zhang, X.; Yazaki, J.; Sundaresan, A.; Cokus, S.; Chan, S.W.L.; Chen, H.; Henderson, I.R.; Shinn, P.; Pellegrini, M.; Jacobsen, S.E., et al. Genome-wide high-resolution mapping and functional analysis of DNA methylation in Arabidopsis. Cell 2006, 126, 1189-1201.

20. Illingworth, R.; Kerr, A.; DeSousa, D.; Jørgensen, H.; Ellis, P.; Stalker, J.; Jackson, D.; Clee, C.; Plumb, R.; Rogers, J., et al. A novel CpG island set identifies tissue-specific methylation at developmental gene loci. PLoS Biology 2008, 6, e22.

21. Hsieh, T.-F.; Ibarra, C.A.; Silva, P.; Zemach, A.; Eshed-Williams, L.; Fischer, R.L.; Zilberman, D. Genomewide demethylation of Arabidopsis endosperm. Science 2009, 324, 1451-1454.

22. Ibarra, C.A.; Feng, X.; Schoft, V.K.; Hsieh, T.-F.; Uzawa, R.; Rodrigues, J.A.; Zemach, A.; Chumak, N.; Machlicova, A.; Nishimura, T., et al. Active DNA demethylation in plant companion cells reinforces transposon methylation in gametes. Science 2012, 337, 1360-1364. 
23. Zemach, A.; Kim, M.Y.; Silva, P.; Rodrigues, J.A.; Dotson, B.; Brooks, M.D.; Zilberman, D. Local DNA hypomethylation activates genes in rice endosperm. Proceedings of the National Academy of Sciences 2010, 107, 18729-18734.

24. Eichten, S.R.; Vaughn, M.W.; Hermanson, P.J.; Springer, N.M. Variation in DNA methylation patterns is more common among maize inbreds than among tissues. The Plant Genome 2013, 6, 1-10.

25. Mayer, K.F.X.; Waugh, R.; Brown, J.W.S.; Schulman, A.; Langridge, P.; Platzer, M.; Fincher, G.B.; Muehlbauer, G.J.; Sato, K.; Close, T.J., et al. A physical, genetic and functional sequence assembly of the barley genome. Nature 2012, 491, 711-716.

26. Brockman, W.; Alvarez, P.; Young, S.; Garber, M.; Giannoukos, G.; Lee, W.L.; Russ, C.; Lander, E.S.; Nusbaum, C.; Jaffe, D.B. Quality scores and SNP detection in sequencing-by-synthesis systems. Genome Research 2008, 18, 763-770.

27. Mahalanobis, P.C. In On the generalised distance in statistics, Proceedings National Institute of Science, India, 1936; pp 49-55.

28. Enot, D.P.; Lin, W.; Beckmann, M.; Parker, D.; Overy, D.P.; Draper, J. Preprocessing, classification modeling and feature selection using flow injection electrospray mass spectrometry metabolite fingerprint data. Nature Protocols 2008, 3, 446-470.

29. Osabe, K.; Clement, J.D.; Bedon, F.; Pettolino, F.A.; Ziolkowski, L.; Llewellyn, D.J.; Finnegan, E.J.; Wilson, I.W. Genetic and DNA methylation changes in cotton (Gossypium) genotypes and tissues. PLoS One 2014, 9, e86049.

30. Kitimu, S.R.; Taylor, J.; March, T.J.; Tairo, F.; Wilkinson, M.J.; Rodriguez Lopez, C.M. Meristem micropropagation of cassava (Manihot esculenta) evokes genome-wide changes in DNA methylation. Frontiers in Plant Science 2015, 6, 1-12.

31. Zhong, S.; Fei, Z.; Chen, Y.-R.; Zheng, Y.; Huang, M.; Vrebalov, J.; McQuinn, R.; Gapper, N.; Liu, B.; Xiang, J., et al. Single-base resolution methylomes of tomato fruit development reveal epigenome modifications associated with ripening. Nature Biotechnology 2013, 31, 154-159.

32. Candaele, J.; Demuynck, K.; Mosoti, D.; Beemster, G.T.S.; Inze, D.; Nelissen, H. Differential methylation during maize leaf growth targets developmentally regulated genes. Plant Physiology 2014, 164, 1350-1364.

33. Brandeis, M.; Ariel, M.; Cedar, H. Dynamics of DNA methylation during development. BioEssays 1993, 15, 709-713.

34. Zhang, X. The epigenetic landscape of plants. Science 2008, 320, 489-492.

35. Bewick, A.J.; Ji, L.; Niederhuth, C.E.; Willing, E.-M.; Hofmeister, B.T.; Shi, X.; Wang, L.; Lu, Z.; Rohr, N.A.; Hartwig, B., et al. On the origin and evolutionary consequences of gene body DNA methylation. Proceedings of the National Academy of Sciences 2016, 113, 9111-9116.

36. Deaton, A.M.; Bird, A. CpG islands and the regulation of transcription. Genes E Development 2011, 25, 10101022.

37. Xie, H.; Konate, M.; Sai, N.; Tesfamicael, K.G.; Cavagnaro, T.; Gilliham, M.; Breen, J.; Metcalfe, A.; Stephen, J.; DeBei, R., et al. Global DNA Methylation Patterns Can Play a Role in Defining Terroir in Grapevine (Vitis vinifera cv. Shiraz). Frontiers in Plant Science 2017, 8.

38. Li-Byarlay, H.; Li, Y.; Stroud, H.; Feng, S.; Newman, T.C.; Kaneda, M.; Hou, K.K.; Worley, K.C.; Elsik, C.G.; Wickline, S.A., et al. RNA interference knockdown of DNA methyl-transferase 3 affects gene alternative splicing in the honey bee. Proceedings of the National Academy of Sciences 2013, 110, 12750-12755.

39. Jones, P.A. Functions of DNA methylation: islands, start sites, gene bodies and beyond. Nature Reviews Genetics 2012, 13, 484-492.

40. Hollister, J.D.; Gaut, B.S. Epigenetic silencing of transposable elements: A trade-off between reduced transposition and deleterious effects on neighboring gene expression. Genome Research 2009, 19, 1419-1428.

41. 40. Druka, A.; Muehlbauer, G.; Druka, I.; Caldo, R.; Baumann, U.; Rostoks, N.; Schreiber, A.; Wise, R.; Close, T.; Kleinhofs, A., et al. An atlas of gene expression from seed to seed through barley development. Functional E Integrative Genomics 2006, 6, 202-211.

42. Orgel, L.E.; Crick, F.H.C. Selfish DNA: the ultimate parasite. Nature 1980, 284, 604-607.

43. Lister, R.; O'Malley, R.C.; Tonti-Filippini, J.; Gregory, B.D.; Berry, C.C.; Millar, A.H.; Ecker, J.R. Highly integrated single-base resolution maps of the epigenome in Arabidopsis. Cell 2008, 133, 523-536.

44. Hirsch, C.D.; Springer, N.M. Transposable element influences on gene expression in plants. Biochimica et Biophysica Acta - Gene Regulatory Mechanisms 2016, 1860, 157-165. 
45. Marquez, Y.; Brown, J.W.S.; Simpson, C.; Barta, A.; Kalyna, M. Transcriptome survey reveals increased complexity of the alternative splicing landscape in Arabidopsis. Genome Research 2012, 22, 1184-1195.

46. Simpson, Craig G.; Lewandowska, D.; Fuller, J.; Maronova, M.; Kalyna, M.; Davidson, D.; McNicol, J.; Raczynska, D.; Jarmolowski, A.; Barta, A., et al. Alternative splicing in plants. Biochemical Society Transactions 2008, 36, 508-510.

47. Barbazuk, W.B.; Fu, Y.; McGinnis, K.M. Genome-wide analyses of alternative splicing in plants: Opportunities and challenges. Genome Research 2008, 18, 1381-1392.

48. Warf, M.B.; Berglund, J.A. The role of RNA structure in regulating pre-mRNA splicing. Trends in biochemical sciences 2010, 35, 169-178.

49. Pan, Q.; Shai, O.; Lee, L.J.; Frey, B.J.; Blencowe, B.J. Deep surveying of alternative splicing complexity in the human transcriptome by high-throughput sequencing. Nature Genetics 2008, 40, 1413-1415.

50. Lorincz, M.C.; Dickerson, D.R.; Schmitt, M.; Groudine, M. Intragenic DNA methylation alters chromatin structure and elongation efficiency in mammalian cells. Nature Structural Molecular Biology 2004, 11, 10681075.

51. Johnston, R.; Wang, M.; Sun, Q.; Sylvester, A.W.; Hake, S.; Scanlon, M.J. Transcriptomic analyses indicate that maize ligule development recapitulates gene expression patterns that occur during lateral organ initiation. The Plant Cell 2014, 26, 4718-4732.

52. Glass, A.D.M.; Shaff, J.E.; Kochian, L.V. Studies of the uptake of nitrate in barley: IV. Electrophysiology. Plant Physiology 1992, 99, 456-463.

53. Tischner, R. Nitrate uptake and reduction in higher and lower plants. Plant, Cell E Environment 2000, 23, 1005-1024.

54. Wise, R.R. The diversity of plastid form and function. In The Structure and Function of Plastids, Wise, R.R.; Hoober, J.K., Eds. Springer, the Netherlands: Dordrecht, 2006; pp 3-26.

55. Berger, B.; Regt, B.; Tester, M. Trait dissection of salinity tolerance with plant phenomics. In Plant Salt Tolerance, Shabala, S.; Cuin, T.A., Eds. Humana Press: 2012; Vol. 913, pp 399-413.

56. Zadoks, J.C.; Chang, T.T.; Konzak, C.F. A decimal code for the growth stages of cereals. Weed Research 1974, 14, 415-421.

57. Xia, Z.; Zou, M.; Zhang, S.; Feng, B.; Wang, W. AFSM sequencing approach: a simple and rapid method for genome-wide SNP and methylation site discovery and genetic mapping. Scientific Reports 2014, 4, 73007308.

58. Poland, J.A.; Brown, P.J.; Sorrells, M.E.; Jannink, J.-L. Development of high-density genetic maps for barley and wheat using a novel two-enzyme genotyping-by-sequencing approach. PLoS One 2012, 7, e32253.

59. Mayne, B.T.; Leemaqz, S.Y.; Buckberry, S.; Rodriguez Lopez, C.M.; Roberts, C.T.; Bianco-Miotto, T.; Breen, J. msgbsR: An R package for analysing methylation-sensitive restriction enzyme sequencing data. Scientific Reports 2018, 8, 2190.

60. Benjamini, Y.; Hochberg, Y. Controlling the false discovery rate: a practical and powerful approach to multiple testing. Journal of the royal statistical society. Series B (Methodological) 1995, 289-300.

61. Dunn, O.J. Multiple comparisons among means. Journal of the American Statistical Association 1961, 56, 5264.

62. Rodríguez López, C.M.; Morán, P.; Lago, F.; Espiñeira, M.; Beckmann, M.; Consuegra, S. Detection and quantification of tissue of origin in salmon and veal products using methylation sensitive AFLPs. Food Chemistry 2012, 131, 1493-1498.

63. Quinlan, A.R.; Hall, I.M. BEDTools: a flexible suite of utilities for comparing genomic features. Bioinformatics 2010, 26, 841-842.

64. Gentleman, R. annotate: Annotation for microarrays. R package version 1.52.0. https://www.bioconductor.org/packages/release/bioc/html/annotate.html (4 March 2017),

65. Carlson, M. GO.db: A set of annotation maps describing the entire gene ontology. R package version 3.4.0. http://bioconductor.org/packages/release/data/annotation/html/GO.db.html (4 March 2017),

66. Supek, F.; Bošnjak, M.; Škunca, N.; Šmuc, T. REVIGO summarizes and visualizes long lists of gene ontology terms. PLoS One 2011, 6, e21800. 